\title{
A Stochastic Simulation Approach to Estimating the Economic Impacts of Climate Change in Bangladesh
}

\author{
James Thurlow ${ }^{1}$, Paul Dorosh, ${ }^{2}$ and \\ Winston $\mathrm{Yu}^{3}$
}

December 2011

\begin{abstract}
Climate change assessments often inadequately address uncertainty when estimating damages. Using a dynamic economy-wide model of Bangladesh, we estimate and decompose damages from historical climate variability and future anthropogenic climate change. Our stochastic simulation approach avoids biases caused by non-linear damage functions and fixed occurrences of extreme events in historical data. Using ten climate projections, we find that future anthropogenic climate change damages until 2050 are, on average, one-fifth of those from historical climate variability. Climate change also alters the temporal distribution of damages and slows Bangladesh's long- run shift (adaptation) into dry (winter) season rice production.
\end{abstract}

Keywords: climate change, uncertainty, stochastic simulation, CGE model, agriculture, Bangladesh

JEL classification: D58, Q54, Q56

${ }^{1}$ UNU-WIDER and International Food Policy Research Institute, email: james@wider.unu.edu, ${ }^{2}$ International Food Policy Research Institute, ${ }^{3}$ The World Bank.

This study has been prepared within the UNU-WIDER project on Development under Climate Change, directed by Channing Arndt.

UNU-WIDER gratefully acknowledges the financial contributions to the project by the Finnish Ministry for Foreign Affairs and the Swedish International Development Cooperation Agency_Sida, and the financial contributions to the research programme by the governments of Denmark (Ministry of Foreign Affairs), and the United Kingdom (Department for International Development). 
The World Institute for Development Economics Research (WIDER) was established by the United Nations University (UNU) as its first research and training centre and started work in Helsinki, Finland in 1985. The Institute undertakes applied research and policy analysis on structural changes affecting the developing and transitional economies, provides a forum for the advocacy of policies leading to robust, equitable and environmentally sustainable growth, and promotes capacity strengthening and training in the field of economic and social policy making. Work is carried out by staff researchers and visiting scholars in Helsinki and through networks of collaborating scholars and institutions around the world.

www.wider.unu.edu

publications@wider.unu.edu

UNU World Institute for Development Economics Research (UNU-WIDER)

Katajanokanlaituri 6 B, 00160 Helsinki, Finland

Typescript prepared by Lisa Winkler at UNU-WIDER

The views expressed in this publication are those of the author(s). Publication does not imply endorsement by the Institute or the United Nations University, nor by the programme/project sponsors, of any of the views expressed. 


\section{Introduction}

Climate change complicates economic development in low-income countries. At the very least, it heightens the uncertainty under which governments must design national strategies (Hassan 2010). Three sources of climate uncertainty can be identified. First, while the distribution of historical climate is known, it is difficult to forecast annual weather patterns, particularly extreme weather events. Second, the global economy's long-term trajectory is unknown, including its structural transformation, population growth, and mitigation policies. Accordingly, future levels of greenhouse gas (GHG) emissions are uncertain. Finally, even with a known emissions trajectory, it is unclear which general circulation model (GCM) best reflects the earthatmosphere relationship. Ideally, impact and vulnerability assessments should reflect these uncertainties and distinguish between historical climate variability and future anthropogenic climate change (Füssel and Klein 2006).

The literature examining the economic impacts of climate change has expanded rapidly (see Füssel and Klein 2006; Tol 2009). Recent studies typically combine biophysical models with global, country, or agricultural sector models (see, for example, Ahmed et al. 2011; Arndt et al. 2011; Block et al. 2008). While these studies have become more detailed, they are often limited in their treatment of uncertainty. For example, some studies rely on only a few climate projections, thus making them sensitive to the uncertainty of global climate modeling (Calzadilla et al. 2009). Other studies avoid issues of historical variability, particularly extreme events, by focusing on incremental climate changes only, sometimes using static two-period analysis (Hertel et al. 2010). Finally, most studies impose mean changes from climate projections onto historical climate series thereby retaining historical variability (Arndt et al. 2011). However, climate damage functions are often non-linear, and so using a single historical weather sequence as a baseline makes the measured impacts of future climate change sensitive to the timing and severity of extreme weather events in the historical data. Thus, while recent impact assessments are more comprehensive and account for a wider range of impact channels, many still do not fully address the issue of climate uncertainty.

We develop a recursive dynamic computable general equilibrium (DCGE) model of Bangladesh. Our dynamic economy-wide framework captures non-linear responses to extreme weather events, and spillover effects across sectors and sub-national regions. We generate a stochastic baseline scenario using Monte Carlo simulations of future weather sequences drawn from the historical climate distribution. This permits the random occurrence of extreme events. Based on crop and river basin modeling results, the DCGE model decomposes the impacts of historical climate variability and anthropogenic climate change. The latter is based on ten combinations of GCM and emissions scenarios. The next section briefly describes the biophysical models from Yu et al. (2010), whose results inform our economic analysis. Section 3 describes the DCGE model and climate simulations. Section 4 presents the simulation results, and the final section summarizes our findings and identifies areas for further research. 


\section{Climate change and biophysical impacts}

\subsection{Climate risk in Bangladesh}

Bangladesh is one of the most vulnerable countries to climate shocks. Most of the population, especially the poor, live in rural areas and depend on agriculture for their livelihoods. High population density means that rural inhabitants are mostly smallholder farmers (less than 0.5 acres) or landless farm workers. Agriculture and downstream processing generate a quarter of gross domestic product (GDP). Rice is the main staple food and accounts for half of crop and agro-processing GDP (Dorosh and Thurlow 2008). Agriculture is also crucial for urban inhabitants given their dependence on domestically-produced foods. Climate shocks affecting agriculture therefore have implications for economic growth, poverty, and food security.

Bangladesh has a long history of climate variability. Figure 1 shows historical economic growth rates. Although total GDP has grown every year since 1975, agricultural growth has been erratic. This is partly because Bangladesh lies at the end of three major river basins and is subject to flooding during the wet season (June-October) and water scarcity during the winter season (November-May). Although monsoonal floods usually benefit agriculture, the infrequent occurrence of major flooding has devastating implications for rural livelihoods and infrastructure (see del Ninno et al. 2001). ${ }^{1}$ Agricultural GDP growth has therefore fluctuated, especially during major flood years. Moreover, much of the country lies at very low altitude and is exposed to cyclones, storm surges, and the possibility of rising sea levels. Anthropogenic climate change may exacerbate existing climatic risks. Below we summarize the biophysical modeling from $\mathrm{Yu}$ et al. (2010) that forms the basis for our economic assessment.

Figure 1: Agricultural and total GDP growth trends, 1975-2009

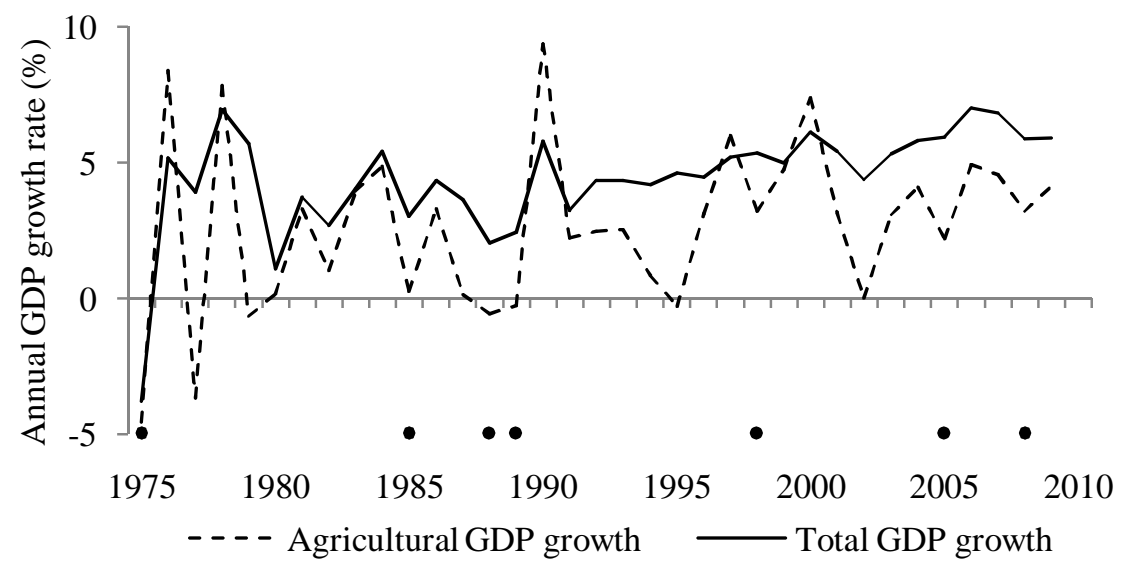

Notes: Black dots represent years where historical climate data indicate major flood occurrences during the crop season (e.g., 1975 calendar year is crop season 1974/75).

Source: Adapted from Yu et al. (2010) using World Bank (2011).

1 Normal floods cover a third of the country for several days or weeks during July/August. In contrast, major or severe floods, like that of 1998, can last until mid-September in some areas. Severe flooding occurs when all three of Bangladesh's river basins experience peak flows at the same time (del Ninno et al. 2001: 3). 


\subsection{Climate change scenarios}

Climate change projections vary across GCMs and across the emissions scenarios defined by the Intergovernmental Panel on Climate Change's (IPCC) special report on emissions scenarios(SRES) (see Arnell et al. 2010). Yu et al. (2010) examine monthly temperature and precipitation projections for Bangladesh using 16 GCMs and three emissions scenarios. Gridded GCM projections were weighted to a national average using the share of each grid within national borders. A 'delta approach' was then used to estimate climate changes using historical baseline climate time series for 1970-99 and mean projected climate changes for the 2030s (2020-49) and 2050s (2040-69). More specifically, the baseline temperature and precipitation levels (and hence variability) are based on observed historical data. To derive future climate change series, we perturb each annual observation in the historical series by the mean temperature and precipitation deviations predicted by the global climate models (from their own modeled baseline). ${ }^{2}$

All GCM/SRES pairings predict rising temperatures, with median warming of $1.1^{\circ} \mathrm{C}$ and $1.6^{\circ} \mathrm{C}$ for the 2030s and 2050s, respectively. Although there is less consistency for the precipitation projections, median results suggest annual precipitation will increase 4percent above the historical baseline by the 2050s. All of the additional precipitation is projected to occur in the wet season, with drier-than-baseline conditions occurring in the dry (winter) season. Both outcomes have implications for annual flooding and crop yields.

A sub-sample of the GCM/SRES projections was used for the biophysical analysis. GCMs were selected so that they (1) adequately capture the three river basins and the dynamics of monsoonal flooding; (2) reflect the full distribution of modeled projections; and (3) have the necessary resolution for the biophysical models. Two emissions scenarios were selected to reflect two possible future states of the global economy. The A2 scenario projects high levels of global emissions due to fast population growth and only limited adoption of more energy-efficient technology. In contrast, the B1 scenario projects lower (but still rising) emissions due to more modest population growth and more widespread diffusion of improved technologies. Ultimately, five GCMs and two emissions scenarios were selected. 3

\subsection{River basin flooding and rising sea levels}

Yu et al. (2010) use a trans-boundary river basin model to estimate water flows into Bangladesh. Inflows were validated and passed down to a national hydrologic model in order to predict daily water levels and discharges. Spatial elevation models interpolated flood surfaces taking account of flood protection infrastructure. The extent, depth and duration of floods were estimated for the historical baseline and for the 2030s and 2050s projections.

2 GCMs are unlikely to accurately forecast weather conditions for a particular year. The delta approach avoids relying on annual predictions and assumes that GCMs are better predictors of changing climate trends. This means that the changes in climate variance predicted by the GCMs are not used directly under the delta approach.

3 SRES: A2 and B1. GCMs: gfdl2.1, miroc3.2_medres, mpi_echam5, ncar_ccsm3, and ukmo_hadcm3. 
Results indicate that, on average, trans-boundary inflows during the wet season increase in the ten GCM/SRES pairings, albeit with wide variation in monthly monsoonal discharges. The average increase in discharge by the 2050s also varies across river basins-from 3.6 percent in Meghna (July) to 17.4 percent in Brahmaputra (May). The national hydrologic model predicts an expansion of flooded areas for most GCM/SRES pairings. The average increase is larger in the A2 scenarios (13 percent) than in the B1 scenarios (7 percent). Floods are also expected to arrive earlier and recede later in the year. Finally, predicted increases in peak flows, while not always statistically significant, suggest that major floods may become more frequent.

Sea level rise reduces land availability in low-lying areas. IWM and CEGIS (2007) estimate that, at the national level, Bangladesh stands to lose 1.5 and 2.5 percent of agricultural land if sea levels rise by 15 and 27 centimeters, respectively. These losses are concentrated in coastal areas (e.g., 17.8 percent of land submerged in the southern Khulna region in the 27 centimeter scenario).

\subsection{Agricultural production changes}

Yu et al. (2010) estimate agricultural yields using the crop environment resource synthesis rice and wheat models. Separate models were employed for the main rice crops: aus (mainly nonirrigated rice), aman (monsoon season rice, historically cultivated with traditional varieties), and boro (winter season irrigated rice). 4 The models were calibrated to the conditions in 16 agroclimatic regions, including weather and soil characteristics and irrigation and input use. Modeled deviations from maximum potential yields can be caused by $\mathrm{CO}_{2}$ enrichment, changes in temperature and precipitation,and water-logging and flooding damages. The timing of climate changes within the growing season is also accounted for. Yield deviations were estimated for the historical climate series and for the 2030s and 2050s projections. Table 1 reports median production-weighted yield deviations caused by climate change.

Table 1: Median changes in national crop production under alternative climate change scenarios (\%)

\begin{tabular}{lllllll}
\hline & \multicolumn{9}{l}{ Climate change scenarios } \\
\cline { 2 - 7 } & A2 and B1 & A2 only & \multicolumn{3}{c}{ B1 only } \\
\cline { 2 - 7 } & $2030 \mathrm{~s}$ & $2050 \mathrm{~s}$ & $2030 \mathrm{~s}$ & $2050 \mathrm{~s}$ & $2030 \mathrm{~s}$ & $2050 \mathrm{~s}$ \\
\hline Aus & -0.27 & -1.52 & -1.11 & -3.51 & -0.14 & 0.01 \\
Aman & -0.37 & -0.62 & -0.42 & -1.49 & -0.37 & -0.40 \\
Boro & -3.06 & -4.74 & -1.68 & -5.54 & -3.76 & -3.54 \\
Wheat & 2.05 & 3.44 & 2.23 & 3.74 & 1.33 & 3.03 \\
\hline
\end{tabular}

Source: Crop modeling results from Yu et al. (2010: 54).

4 In 2005, boro accounted for 39.2 percent of rice area cultivated and 55.0 percent of production; aman accounted for 50.9 percent of rice area and 39.0 percent of production. Aus accounted for the remainder. 
The onset and duration of annual flooding largely determines agricultural performance in Bangladesh. Rice cultivated in the aman (monsoon) season, can be severely damaged by excessive flood waters during the early growing season, and aman production has fallen sharply in years of major floods when flood waters have failed to recede in time. The projected increase in precipitation and flooding caused by climate change therefore explains most of the decline in aman yields reported in Table 1. In contrast, boro rice, cultivated in the drier, winter season, is most sensitive to the availability of irrigation water. Boro yields fall as a result of climate change due to, on average, declining precipitation and water availability during the winter season. Declining rice yields caused by higher temperatures, precipitation and flooding, however, are partly offset by higher $\mathrm{CO}_{2}$ levels in the atmosphere and $\mathrm{CO}_{2}$ enrichment explains the higher wheat yields caused by climate change. 5 Overall, rice and wheat yield deviations are typically larger by the 2050s and for the A2 scenarios.

In summary, climate change increases Bangladesh's exposure to climate risks. We focus on the agricultural impact channel given the sector's vulnerability to historical and anthropogenic climate changes, and its importance for national income and welfare. Biophysical modeling results indicate worsening flooding and declining rice yields in much of the country as a result of climate change. There is, however, wide variation in outcomes across GCM/SRES pairings.

\section{Stochastic economy-wide modeling framework}

\subsection{Climate simulations and uncertainty}

We conduct three sets of simulations that allow us to address the issues of uncertainties mentioned earlier, and to distinguish between historical climate variability and future anthropogenic climate changes during 2005-50.

Optimal climate: In this first scenario we assume that Bangladesh is unaffected by either natural or anthropogenic climate changes (i.e., every year has the same 'good' weather conditions). Crop yields, productivity, and factor supplies therefore increase smoothly at long-term potential growth rates. This simulation provides a hypothetical 'no climate' scenario against which we can compare climate-affected simulations.

Historical variability: We now introduce historical climate variability. The model is run over 45 years (i.e., 2005-50) and for each simulation year we randomly draw a year from the historical climate data (i.e., 1970-99). We impose on the DCGE model the predicted yield deviations from a maximum potential yield for that historical year using the sub-national crop modeling results. If a major flood year is drawn from the historical series, then additional impacts are imposed (see below). 6 Together these random selections produce a 45 -year weather sequence based on the historical climate distribution. We construct 50 of these 45 -year sequences for our Monte Carlo

5 The inclusion of $\mathrm{CO}_{2}$ enrichment suggests that our results may be overly optimistic (see Cassman et al. 2010).

6 Major flood years in the 1970-99 historical climate data include the following seasons: 1970/71, 1974/75, 1984/85, 1987/88, 1988/89, and 1998/99. 
analysis. The difference between the optimal scenario and an average of the historicalvariabilityscenarios is the estimated impact of historical climate variability. It should be noted that the historical climate series may include some anthropogenic climate change. However, the effects are likely to have been fairly modest during 1970-99, and so when making random draws from the historical series, we assume that the historical data does not contain changes in trend weather conditions caused by anthropogenic climate change (i.e., the weather conditions experienced in 1970 and 1999 were equally likely to reoccur in our base year, 2005).

Climate change: Perturbing historical climate data with the mean temperature and precipitation deviations-from-baseline ('deltas') from the GCM/SRES projections generates two 30-year climate series (i.e., for the 2030s and 2050s) (see explanation in Section 2). To construct the historical variability scenarios described above, we randomly drew observations from the historical climate series to produce a single 45-year weather sequence. Each annual weather condition corresponds to an estimated crop yield deviation. To incorporate future anthropogenic climate change, we maintain the same randomly-drawn annual sequences, now use the information on yield deviations contained in both the historical and projected climate series. As before, we initially draw yield deviations based on the historical climate series. However, as the DCGE model runs forward over 45 years, we smoothly transition to using the estimated yield impacts corresponding to the two projected climate series. For example, 30 years separate the DCGE model's 2005 base year and the mid-point of the 2030s dataset. Therefore in 2010, which is year five in our simulations, we take $25 / 30$ of the yield deviation estimated using the historical series and 5/30 of yield deviation estimated using the 2030s series. The corresponding weights for year six are 24/30 and 6/30, until by 2035 when the entire yield deviation is drawn from the 2030s series. We similarly transition from the 2030s to the 2050s series during the second portion of the simulation period (i.e., 2035-50). We construct 50 45-year sequences for each GCM/SRES pairing, and compare the average result to that of the average historical variability scenario to determine the expected impact of climate change (i.e., the historical scenario is our stochastic 'baseline'). This approach allows us to capture the altering of climate trends due to anthropogenic climate change, while retaining the same underlying climate variability in both the historical variability and climate change scenarios.

\subsection{DCGE model specification}

Below we specify the economy-wide model described in Diao and Thurlow (forthcoming). Consumers and producers in the model are treated as individual economic agents. Under a StoneGeary function, consumers maximize utility subject to a budget constraint. This generates a linear expenditure system of demand functions

$$
P_{i} \cdot C_{i j}=P_{i} \cdot \gamma_{i j}+\beta_{i j} \cdot\left(\left(1-s_{r}-t d_{r}\right) \cdot Y_{j}-\sum_{i \prime} P_{i \prime} \cdot \gamma_{i \prime j}\right)
$$

where $C$ is consumption of good $i$ in region $j, \gamma$ is a minimum subsistence level, $\beta$ is the marginal budget share, $P$ is the market price of each good, $Y$ is total household income, and $s$ and $t d$ are savings and direct tax rates, respectively. Similarly, producers maximize profits subject to given 
input and output prices. Assuming constant returns to scale, a constant elasticity of substitution (CES) function determines production

$$
X_{i j}=\alpha_{i j} \cdot\left(\delta_{i j} \cdot L_{i j}^{-\rho_{i j}}+\left(1-\delta_{i j}\right) \cdot K_{i j}^{-\rho_{i j}}\right)^{-1 / \rho_{i j}}
$$

where $X$ is output quantity of sector $i, \alpha$ is a shift parameter reflecting total factor productivity (TFP), $L$ and $K$ are labor and capital demand, and $\delta$ is a share parameter. The elasticity of factor substitution is a transformation of $\rho$ (i.e., $\sigma=1 /(1+\rho)$ ). Maximizing profits subject to Equation (2) and rearranging the first order condition gives a system of factor demand equations

$$
\frac{L_{i j}}{K_{i j}}=\left(\frac{R_{i j}}{W_{j}} \cdot \frac{1-\delta_{i j}}{\delta_{i j}}\right)^{1 /\left(1+\rho_{i j}\right)}
$$

where $W$ is the area-specific labor wage, and $R$ is the sector/area-specific capital rental rate. For ease of exposition, we do not show intermediate demand in the equations. The producer price $P X$ is the sum of factor payments per unit of output

$$
P X_{i j} \cdot X_{i j}=W_{j} \cdot L_{i j}+R_{i j} \cdot K_{i j}
$$

Products are traded in national markets, implying a single market-clearing price $P$ for each good. Inadequate internal trade data necessitates this assumption. Output from each area is combined into a composite national good $Q$ using a CES function

$$
Q_{i}=\phi_{i} \cdot\left(\sum_{j} \lambda_{i j} \cdot X_{i j}^{-\tau_{i}}\right)^{-1 / \tau_{i}}
$$

Equation 5 permits imperfect substitution between goods from different regions. Relative producer prices are determined by the following first order condition, derived from minimizing the composite supply price of each good:

$$
P X_{i j}=P_{i} \cdot\left(1-t i_{i}\right) \cdot Q_{i} \cdot\left(\sum_{j \prime} \lambda_{i j \prime} \cdot X_{i j^{\prime}}^{-\tau_{i}}\right)^{-1} \cdot \lambda_{i j} \cdot X_{i j}^{-\tau_{i}-1}
$$

where $t i$ is the indirect tax rate applied to domestic sales.

For ease of exposition, the variables and equations governing international trade are not shown. However, our model permits two-way trade by assuming imperfect substitution between domestic and foreign goods (see Armington 1969). More specifically, a constant elasticity of 
transformation function determines exports, and a CES function determines imports. ${ }^{7}$ World prices are fixed under the small country assumption. The current account balance is held constant (in foreign currency units) by allowing the real exchange rate to adjust (i.e., a price index of tradable to non-tradable goods).

Assuming that all factors in an area are owned by households in that area, total income $Y$ is

$$
Y_{j}=\sum_{i}\left(W_{j} \cdot L_{i j}+R_{i j} \cdot K_{i j}\right)+h_{j}
$$

where $h$ is transfer payments from the government (e.g., social grants).

The government is a separate agent with revenues and expenditures, but without any behavioral functions. Total revenue is the summation of direct and indirect taxes, as shown on the left-hand side of the following equation

$$
\sum_{j} t d_{j} \cdot Y_{j}+\sum_{i} t i_{i} \cdot P_{i} \cdot Q_{i}=\sum_{i} P_{i} \cdot A \cdot q g_{i}+\sum_{j} h_{j}+B
$$

Revenues are used to purchase goods and make transfers (i.e., recurrent spending) and to save (i.e., finance public capital investment). This is shown on the right-hand side of Equation (8). Our macro-economic closure rule assumes that public consumption spending is equal to baseyear quantities $q g$ multiplied by an exogenous adjustment factor $A$. The fiscal balance $B$ adjusts to ensure total revenues equal total expenditures in equilibrium.

There is also no behavioral function determining investment demand for each good. We assume a savings-driven closure, i.e., total investment adjusts to match the level of savings in the economy. As shown below, a national savings pool finances investment

$$
\sum_{j} s_{j} \cdot Y_{j}+B=\sum_{i} P_{i} \cdot I \cdot q i_{i}
$$

where qi is base-year investment quantities multiplied by an endogenous adjustment factor $I$.

We assume that labor is fully employed. As such, total labor supply $L S$ in each region is fixed and, in equilibrium, must equal the sum of all sector labor demands

7 Foreign trade decisions take place in national markets (i.e., export and import relative prices are compared to the price of the national composite good $Q$ ). 


$$
L S_{j}=\sum_{i} L_{i j}
$$

Unlike labor, which is mobile across sectors, capital is both sector- and region-specific. Capital demand $K$ in each sector and region are fixed (see Equation 3). The rental rate $R$ adjusts so that the sector/region-specific profit rate equates capital demand and supply in each sector.

Finally, product market equilibrium requires that the composite supply of each good $Q$ equals total private and public consumption and investment demand

$$
Q_{i}=\sum_{j} C_{i j}+A \cdot q g_{i}+I \cdot q i_{i}
$$

Market prices $P$ adjust to maintain equilibrium. Together, the above 11 equations simultaneously solve for the values of 11 endogenous variables (i.e., $C, X, L, R, Q, P X, Y, B, I, W$, and $P$ ). The national consumer price index is selected as a numéraire.

\subsection{Recursive dynamics}

Our model is recursive dynamic; i.e., it consists of distinct within- and between-period components. The above equations specify the within-period component. Between-periods, certain exogenous variables are updated based on either externally-determined trends or previous period results. Exogenous trends include labor supply growth rates (i.e., $L S$ in Equation 10) and rates of technical change (i.e., $\alpha$ in Equation 2).

Although not shown in Equations 1-11, each variable has a time subscript associated with it. Sectorlevel capital accumulation rates are determined endogenously based on investment levels from the previous period. The quantity of new capital $N$ depends on the total value of investment and the capital price $P K$ (i.e., a composite price index derived from investment demand shares $q i)$. New capital is allocated across sectors/regions after applying a national depreciation rate $v$ and according to a capital allocation factor $S K(0<S K<1)$.

$$
\begin{gathered}
N_{t}=\sum_{i}\left(P_{i t} \cdot I_{t} \cdot q i_{i}\right) \cdot P K^{-1} \\
K_{i j t+1}=K_{i j t} \cdot\left(1-v_{i}\right)+S K_{i j t} \cdot N_{t}
\end{gathered}
$$

SK specifies how much investment is directed towards each sector/region and so sums to one. Following Dervis et al. (1982), SK is defined as follows 


$$
S K_{i j t}=S P_{i j t}+\varphi \cdot S P_{i j t} \cdot\left(\frac{R_{i j t}-A R_{t}}{A R_{t}}\right)
$$

where $S P$ is a sector/region's current share in aggregate profits, $R$ is a sector/region's profit rate, and $A R$ is the average profit rate. New capital is allocated in proportion to each sector/region's share in aggregate capital income, adjusted by its profit rate relative to the average profit rate. Sectors/regions with above-average profit rates receive a greater share of investible funds than their share in aggregate profits. The term $\varphi$ is an investment mobility parameter. 8 This allocation procedure is known as a 'putty-clay' specification, since new capital is mobile, but installed capital is not.

\subsection{Climate impact channels}

Three climate impact channels are captured in the DCGE model. The first is changes in crop productivity. As shown below, TFP $(\alpha)$ in each sector/region grows at a long-term rate $\gamma$

$$
\alpha_{i j t}=\alpha_{i j t-1} \cdot\left(1+\gamma_{i j}\right) \cdot\left(\omega_{i r t} \cdot v_{i r t}\right)
$$

The crop models estimate annual crop yield deviations from maximum potential yields. The first parameter $\omega$ varies around a base year value of one depending on the randomly selected year from the climate data series $(0<\omega<\infty) .9$ The second parameter $v$ is caused by water-logging $(0<v \leq 1)$. These yield adjustment factors compound each other, and when their product is less than one, yields fall below long-term trends. Agricultural land cannot be reallocated between crops within each season, although consumers can substitute between aus, aman, and boro rice crops. 10 Yields return to trend levels if weather conditions permit (i.e., no lasting effects).

The second channel is the additional economic losses incurred during extreme weather events. Although not shown in the above equations, the model separates labor and agricultural land within each region. Equation 16governs the expansion of regional land supply NS, whichequals the sum of sector land demands within each period

$$
N S_{j t}=\varepsilon_{j t} \cdot \lambda_{j t} \cdot N S_{j t-1} \cdot\left(1+\varphi_{i j}\right)
$$

8 Following Dervis et al. (1982), we set the value of $\varphi$ at two.

9 All yield deviations from the crop models are less than 1 (i.e., less than the maximum potential yield). However, the 2005 base-year of the DCGE model was a less-than-optimal year and so the yield adjustment factor $\omega$ may exceed one.

10 Almost all rice produced and consumed in Bangladesh is some type of coarse, non-aromatic rice with little quality dinstinction across seasons/varieties. We therefore model a single milled rice commodity market. 
Four lasting impacts occur when a major flood year is drawn from the climate data series (over and above temporary yield deviations). First, agricultural land expansion is normally set at the long-term rate $\varphi$, but ceases during major flood years (i.e., $\varphi=0$ in affected regions). It returns to trend in subsequent years.Second, historical data indicates that the harvested land area of aus and aman rice falls during major flood years due to prolonged water inundation. Accordingly, the parameter $\varepsilon$, which is normally equal to one, declines based on the land losses observed in historical production data during major flood years. Third, long-term improvements in agricultural productivitystop during flood years (i.e., $\gamma=0$ in affected regions-see Equation 15). Finally, infrastructure is damaged during major flood years. The annual capital depreciation rate $v$ in Equation (13)is increased from 0.05 to 0.075 in flood years and to 0.10 in severe flood years (i.e., 1988/89 and 1998/98). This is assumed to only affect agro-processing and trade and transport services, given that they are more likely to be rural-based.

The third impact channel is the rising sea level caused by climate change. Section 2 discussed the estimated land losses for 15 and 27 centimeter scenarios. We assume these correspond to the 2030s and 2050s periods, respectively. Land losses are permanently imposed on the DCGE model. We gradually reduce $\lambda(0 \leq \lambda \leq 1)$ from its base value of one, to levels that reflect the predicted land area reductionsin coastal regions from IWM and CEGIS (2007). Sea level rises are only imposed in the climate change scenarios, although the impacts are assumed to be the same for all GCM/SRES pairings.

In summary, the model captures three climate-related impact channels: (1) climate-induced yield deviations from the crop models; (2) reduced land and capital supplies and factor productivity during major flood years; and (3) declining agricultural land availability due to rising sea levels. The model also simulates increased frequency of major flooding due to climate change. The return periods for the 1988 and 1998 floods are reduced by one-third. More specifically, the 1988 and 1998 floods were 1-in-33 and 1-in-50 years events, respectively (based on river discharges). The frequency of these floods in the sample used to randomly generate future weather sequences is increased to 1 -in-25 and 1-in-33, respectively. This only occurs in the climate change scenarios.

\subsection{Model calibration}

The model is calibrated to a detailed 2005 social accounting matrix (SAM) (Dorosh and Thurlow 2008). The SAM identifies 36 sectors in the 16 agro-climate regions (17 sectors in agriculture, 14 in industry, and 5 in services). Base-year production quantities and yields are calibrated to the Agricultural Sample Survey (BBS 2005a). Substitution elasticities for the production and trade functions are based on cross-country estimates from Dimaranan (2006).

Using the household income and expenditure survey (BBS 2005b), labor markets in each region are segmented by education groups: no schooling; primary schooling; secondary schooling, and tertiary educated. Farm land and agricultural sectors are divided by region and, within each region, into marginal (<0.5 hectares), small-scale (0.5-2.5 hectares), and large-scale farms ( $>2.5$ hectares). Households within each region are divided into farm and non-farm groups, and farm households are divided into landowners and landless farm workers (according to the household head's occupation). Landowning farm households are separated into marginal, small-, and large- 
scale farmers. Non-farm households are split into four groups depending on the education level of the household head. The DCGE model is therefore a very detailed representation of the Bangladesh economy, particularly of the country's agricultural sector.

\section{Simulation results}

\subsection{Optimal scenario}

The optimal scenario provides a growth path for Bangladesh that excludes crop yield losses and flooding damages caused by less-than-optimal weather conditions. 'Optimal' is defined as the highest crop yield achieved in each region within the 30-year historical period (i.e. 1970-99), as estimated by the crop models. Economic growth in the DCGE model is driven by long-run rates of factor accumulation and technical change. Assuming a constant dependency ratio, the growth in population and labor supply gradually decelerates from 2.0 per year in 2005 to 0.5 percent per year in 2050. The supply of better-educated labor expands faster than for uneducated labor, reflecting expected improvements in labor quality. The expansion of agricultural land decelerates from 1.0 per year in 2005 to 0.5 percent per year in 2050. This is slower than rural population growth and reflects rising land scarcity. Capital accumulation is endogenously determined in the model, and capital-output ratios are selected to track long-term capital stock growth. We assume that non-agricultural TFP grows faster (at 2.5 percent per year) than agricultural TFP (2.0 percent).

Total GDP in the optimal scenario grows at an average 4.7 percent per year during 2005-50. Slower agricultural productivity growth causes agriculture's share of GDP to fall from 20.7 percent in 2005 to 12.1 percent in 2050. Since agriculture is the main climate impact channel in our model, its declining contribution to GDP has implications for climate's damage estimates. Negative impacts from climate change on agricultural production will be partly offset by the sector's declining importance in the broader economy. The optimal scenario is itself subject to uncertainty. However, the scenario's assumptions do not greatly influence our conclusions since it is merely used for counter-factual analysis. Overall, it provides a reasonable trajectory for Bangladesh, including expected structural transformation. We now impose the effects of historical climate variability and future climate changes.

\subsection{Historical climate variability scenarios}

The historical scenario includes the yield deviations estimated by the crop and flooding models using historical climate data for 1970-99. Historical variability is defined as the ratio of the estimated annual yield to the maximum yield for the historical period. We also impose additional land and productivity losses during major flood years (see Section 3). We simulate 50 45-year weather sequences drawn randomly from historical data and compare the average outcome to the optimal scenario.

The DCGE model includes some autonomous adaptation. At the producer level, productive resources can be endogenously reallocated away from the worst-affected sectors (e.g., workers' can migrate to other farm and non-farm activities). Reducing agriculture's resources may benefit 
non-agricultural sectors, although this may be offset by inter-industry linkages (i.e., declining availability of intermediate inputs). We adopt the 'dumb farmer' approach when deciding crop land allocations (i.e., farmers see long-term climate trends, but do not anticipate weather conditions within a given year) (see Füsseland Klein 2006). At the national level, Bangladesh adapts to regional production shocks by sourcing products from less-affected regions, albeit at higher prices, or increasing foreign imports, with implications for the country's balance of payments and real exchange rate. Given these endogenous adaptation responses, the results of the DCGE model are not a simple summation of the production changes estimated by the crop models.

Figure 2 shows the estimated losses in national per capita rice production. In the optimal scenario, production grows at three percent per year during 2005-50. In physical terms, domestic production rises from 25.2 to 96.3 million metric tons between 2005 and 2050 (i.e., from 182.8 to 286.9 kilograms per capita). Historical climate variability introduces variation in inter-annual rice production, although, on average, it reduces rice production below optimal'non-climate' levels. Annual production growth falls to 2.7 percent in the average historical sequence, implying that national production reaches only 83.9 million tons by 2050. This is 12.3 million tons below optimal levels (i.e., 36.8 kilograms less per person per year).

Figure 2: Per capita rice production in the historical variability scenarios, 2005-50

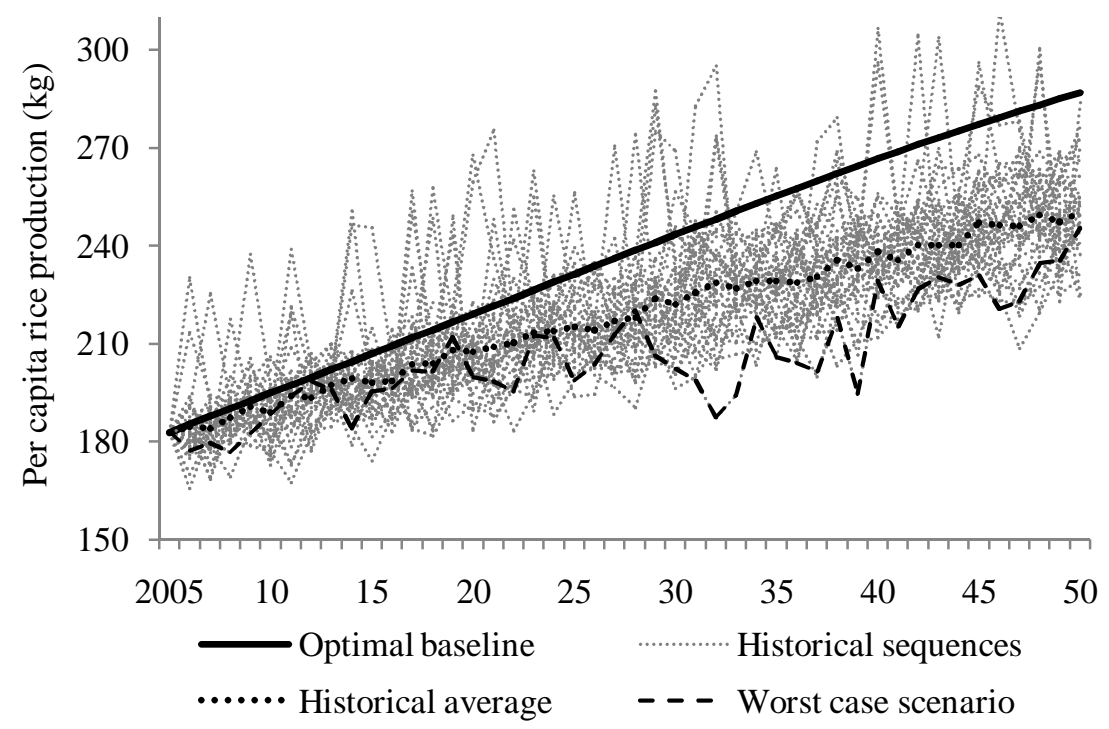

Notes: 'Historical sequences' are 50 randomly-drawn weather simulations (not individually labeled); 'Historical average' is the mean of the historical sequences; 'Worst case scenario' is the historical sequence producing the least rice over the simulation period.

Source: DCGE model results.

The absolute negative impact of historical climate variability on rice production rises over time due to the lasting effects of yield losses and flooding damages on economic growth (i.e., slower capital accumulation and lower long-term productivity). Averaged over the entire simulation period, historical climate variability reduces national rice production by 8.8 percent. We define 
the 'worst case' scenario as the randomly drawn weather sequence resulting in the lowest cumulative production throughout the period 2005-50. In the worst-case scenario, average rice production losses are larger at 14.3 percent.

Yield deviations vary across the three rice varieties (see Table 1). Figure 3 indicates that most of the decline in national rice production in the historical scenario is caused by aus and aman. The average annual growth rates of aus and aman rice production are 0.6 percentage points below the optimal scenario. Although boro rice production falls in certain weather sequences, its average production level remains virtually unchanged from optimal levels. This is consistent with Bangladesh's historical agricultural strategy to promote production of dry (winter) season boro rice. In fact, the expansion of boro rice production during the 1990s partly explains why the major 1998 floods (i.e., 1-in-100 year event) had a smaller impact on national rice production and agricultural GDP than the less-severe 1988 floods (del Ninno et al. 2001: 39). ${ }^{11}$

Figure 3: Production results for the historical variability scenarios, 2005-50

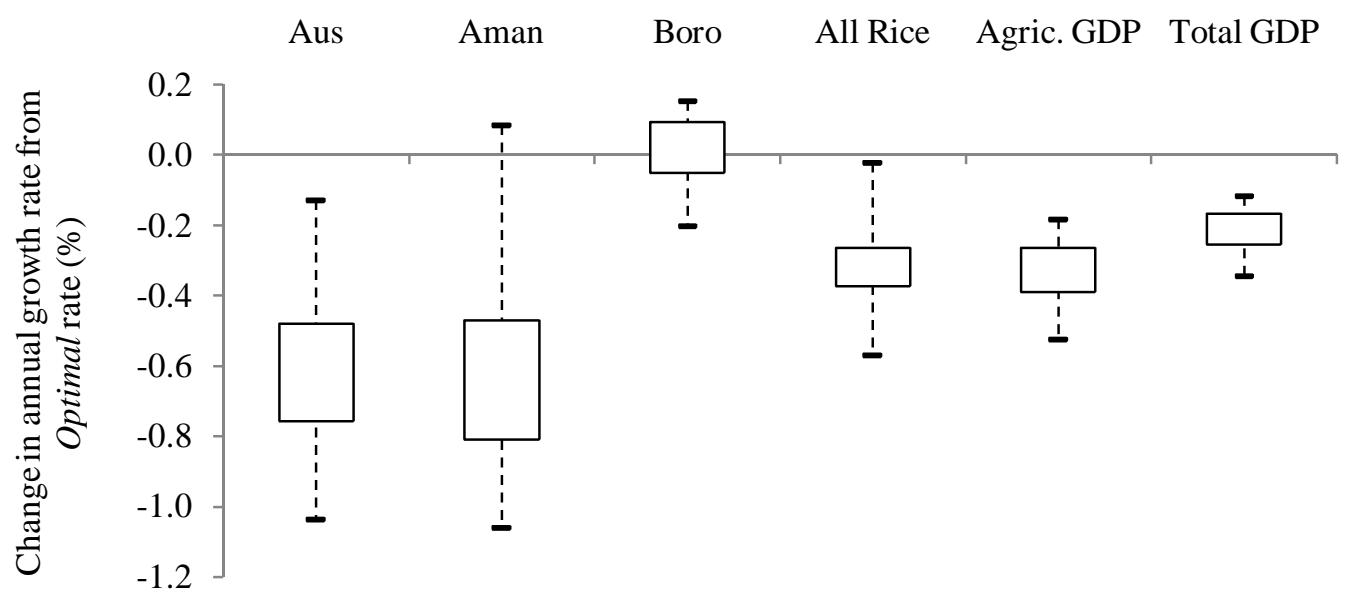

Source: DCGE model results.

Rice and wheat account for almost half of crop GDP. Together with sector-wide flood damages, the reduction in these crops' yields causes agricultural GDP to fall below the optimal scenario (see Figure 3). Moreover, agriculture's large contribution to the overall economy means that total GDP is also noticeably affected. This national impact is compounded by inter-industry linkages, in which the supply of agricultural goods to downstream sectors declines along with agriculture's demand for non-agricultural inputs (e.g., fertilizer and transport services). Moreover, falling rural incomes reduce demand for final non-agricultural foods. Finally, flooding directly damages capital stocks in certain non-agricultural sectors. Thus, despite our focus on agricultural impact channels, our results reveal large economy-wide damages from historical climate variability.

11 The optimal baseline scenario does not simulate any future switch from aus/aman to boro rice. This would lower the future national production losses caused by historical climate variability. However, our focus is to compare historical variability and future climate change scenarios, and these are both referenced to the same baseline. 
On average, total GDP's annual growth rate is 0.2 percentage points below the optimal scenario during 2005-50. Small reductions in growth rates can lead to large absolute losses when compounded over 45 years. Part 1 of Table 2 shows that the cumulative difference in total GDP between the optimal and historical scenarios amounts to US\$597.1 billion (measured in 2005 prices). Applying a 5 percent discount rate, total losses are US\$120.7 billion or an average US $\$ 2.7$ billion per year. By the 2040s, total GDP is 4.7 percent below what would have been achieved without the adverse effects of historical climate variability.

Table 2:Economic losses in the historical and climate change scenarios

\begin{tabular}{|c|c|c|c|c|}
\hline & \multirow{2}{*}{$\begin{array}{l}\text { Historical } \\
\text { variability }\end{array}$} & \multicolumn{3}{|c|}{ Climate change } \\
\hline & & $\begin{array}{l}\text { A2 and } \\
\text { B1 }\end{array}$ & A2 only & B1 only \\
\hline Cumulative loss $^{1}$ (US\$ bil.) & 594.1 & 128.6 & 146.8 & 110.3 \\
\hline $\begin{array}{l}\text { Discounted cumulative } \text { loss }^{2} \\
\text { (US } \$ \text { bil.) }\end{array}$ & 120.7 & 25.7 & 29.2 & 22.3 \\
\hline Share of GDP,2040s (\%) ${ }^{3}$ & 4.71 & 1.04 & 1.18 & 0.90 \\
\hline
\end{tabular}

Notes: ${ }^{1}$ Change in total GDP measured in 2005 prices; ${ }^{2}$ discounted at 5 percent per year; ${ }^{3}$ decline in GDP as a share of optimal or historical GDP for the historical or climate change scenarios, respectively.

Source: DCGE model results. Adapted from Yu et al. (2010: 70, 78).

\subsection{Future climate change scenarios}

Building on the historical variability scenario, we now include the additional impacts of anthropogenic climate change. As described in Section 3, we randomly draw 50 45-year weather sequences by smoothly transitioning from yield deviations based on the historical climate series to yield deviations based on the 2030s and 2050s series. The latter include both historical variability and future climate change. Therefore, to isolate the effects of climate change we compare the results of the climate change scenarios to the average historical scenarios. To account for the uncertainties of global economy and climate system modeling, we estimate climate change impacts for the ten GCM/SRES pairings (see Section 2).

Figure 4 shows the estimated losses in national per capita rice production. The lighter curves are average outcomes for each GCM/SRES pairing. These are based on the same 50 weather sequences underlying the average historical scenario. As such, differences between the GCM/SRES curves are solely due to global economy and climate model uncertainty. The average climate change scenario is the arithmetic mean outcome of all ten GCM/SRES pairings. Although we attempted to reflect the full distribution of IPCC projections when selecting GCM/SRES pairings, we cannot be certain that the IPCC projections themselves reflect the full distribution of possible climate changes. Moreover, we assume that GCM/SRES pairings can be assigned the same weight. Recognizing these shortcomings, we define the difference between the climate change and historical scenarios as the economic impact of anthropogenic climate change. 
Figure 4: Per capita rice production for the climate change scenarios, 2005-50

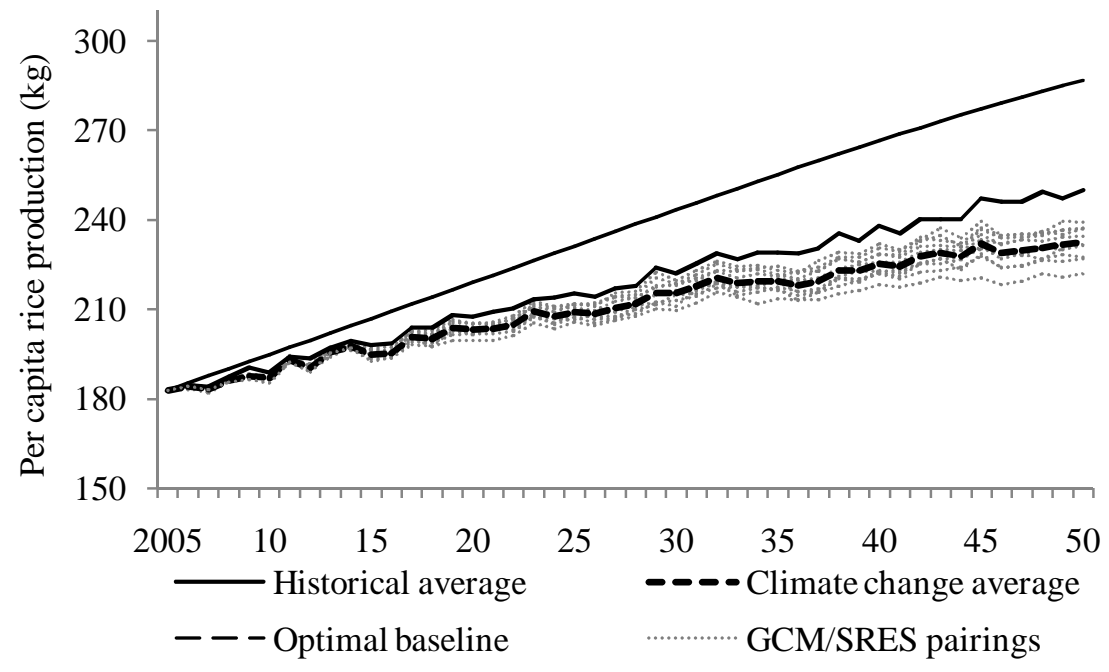

Notes: 'Historical average' is the mean of 50 weather simulations randomly drawn from historical data; GCM/SRES pairing' is the mean of 50 weather simulations drawn from each of the ten projected climate change series (not individually labeled); 'Climate change average' is the mean of the ten GCM/SRES pairings.

Source: DCGE model results.

Figure 5: Production results for the climate change scenarios, 2005-50

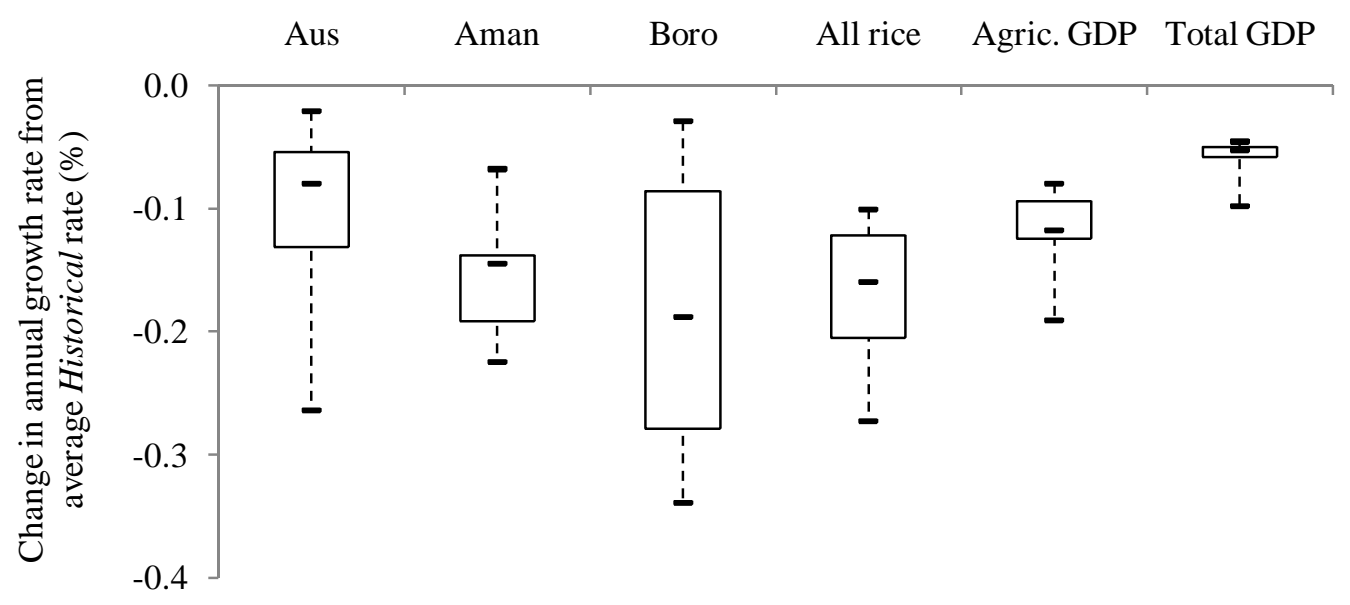

Source: DCGE model results.

National rice production declines under all GCM/SRES pairings. The average annual growth rate for 2005-50 falls from 2.7 percent in the historical scenario to 2.5 percent per year in the averageclimate change scenario. Slower production growth (i.e., by 0.16 percentage points) lowers national rice production in 2050 by 5.9 million tons (i.e., 15.5 kilogram per capita). 
Figure 5 indicates that this fall in production is driven by declines in all three rice varieties, although the largest average decline is for boro rice. The average growth rate for boro production falls by 0.2 percentage points. Since major flooding does not occur during the winter season, this reduction in boro production is driven by falling crop yields (see Table 1). While aus and aman production also declines, the losses are smaller than for boro. This is despite the two wet season varieties being exposed to more frequent major flooding.

Figure 5 also reports declines in average GDP growth. On average, agricultural GDP's annual growth rate is 0.1 percentage points lower as a result of climate change. Again, agriculture's large contribution to the overall economy and its linkages to non-agriculture mean that total GDP also declines in the climate changescenarios. Part 2 of Table 2 reports the economic losses caused by climate change over the 45-year simulation period. The discounted cumulative loss in value added is US $\$ 25.7$ billion for 2005-50, or an average US\$570 million per year (measured in 2005 prices). By the 2040s, total GDP is about one percent smaller than it would have been in the absence of anthropogenic climate change. This is roughly a fifth of the damages caused by historical variability.

Uncertainty over future GHG emissions is reflected in the difference between changes in total GDP for the average A2 and B1 scenarios. Discounted economic losses are higher for the average A2 scenario (US\$22.3 billion) than for the B1 scenario (US\$22.3 billion). Moreover, incorporating GCM uncertainty broadens the range of outcomes even further (i.e., from US\$18.4 billion under miroc3.2/B1 to US\$46.1 billion for gdfl2.1/A2). This variation in damage estimates underscores the importance of considering a range of climate change projections in impact and vulnerability assessments. However, even in the worst climate change scenario, damages are less than half those caused by historical climate variability. It is therefore also important to situate the damages from anthropogenic climate change within the historical context.

\section{Conclusions}

We have developed a recursive dynamic CGE model in order to estimate the economic impacts of future anthropogenic climate changes and to distinguish them from historical climate variability. Our findings indicate that, on average, historical climate variability will reduce national rice production in Bangladesh by 8.8 percent over 2005-50, primarily as a result of flooding damages to wet season rice varieties. The importance of agriculture in the broader economy means that both agricultural and total GDP decline. The loss in total GDP from historical climate variability amounts to US\$2.5 billion per year (measured in 2005 prices and with a 5 percent annual discount rate). In contrast, the GDP damages caused by anthropogenic climate change are five times smaller. Climate change damages will, however, increase with time and may become more pronounced beyond our simulation period (i.e., post-2050s).

Anthropogenic climate change also alters the seasonal distribution of climate damages in Bangladesh. Unlike historical variability, climate change reduces dry (winter) season (irrigated) boro production by more than wet season aus and aman. This remains true even when we increase the frequency of major monsoonal flooding. Therefore, not only will climate change 
heighten food insecurity in Bangladesh, but it will tend to slow the long-run shift in importance of wet season relative to dry (winter) season rice cultivation.

Methodologically, our stochastic derivation of a baseline scenario approximates future weather patterns based on the historical climate distribution. This approach retains the non-linear effects of extreme weather events, but allows these to appear randomly in the baseline. This is an advance on previous studies that define baseline scenarios as simple repetitions of historical climate series. Using a single sequence of historically-observed weather outcomes as a baseline biases damage estimates when damage response functions are non-linear. For example, with nonlinear responses and climate change becoming more pronounced with time, the economic impact of climate change is larger when extreme events occur later in the baseline. This makes it difficult to determine how much of the estimated damages are due to the choice of baseline and how much are due to projected climate changes. Decomposing historical variability and future climate changes therefore requires a stochastic approach.

Our analysis can be extended. First, we focus on agriculture, but more comprehensive studies capture a range of impact channels, such as urban and coastal infrastructure, hydropower and human health (see, for example, Arndt et al. 2011). Second, while the 'dumb farmer' assumption is commonly used in economic modeling, it should be replaced by more flexible endogenous/autonomous adaptation responses (see Füssel and Klein 2006). Third, our stochastically-generated baseline did not allow for the possibility of serial correlation when drawing annual weather events from the historical distribution. Fourth, the delta approach to incorporating climate change projections did not consider the changes in variance predicted by the GCMs. While ours is the approach usually adopted in country impact assessments, the importance of extreme weather events means that further investigation into changing weather variance due to climate change is warranted. Finally, our economic model was of Bangladesh only and permitted food imports at fixed world prices. Global models, which simultaneously estimate climate damages in all countries, can predict changes in world prices and trade flows. However, global models forfeit country level detail, including the seasonal and spatial production patterns that underpin our findings for Bangladesh.

\section{References}

Ahmed, S.A., N.S. Diffenbaugh, T.W. Hertel, D.B. Lobell,N. Ramankutty, A.R. Rios, and P. Rowhani, 'Climate Volatility and Poverty Vulnerability in Tanzania,' Global Environmental Change 21 (2011):46-55.

Armington, P.A., 'A Theory of Demand for Products Distinguished by Place of Production,'IMF Staff Papers 16(1969):159-78.

Arndt, C., K. Strzepek, F. Tarp, J. Thurlow, C. Fant, and L. Wright, 'Adapting to Climate Change: An Integrated Biophysical and Economic Assessment for Mozambique,' Sustainability Science 6 (2011):7-20.

Arnell, N.W., M.J.L. Livermore, S. Kovats, P.E. Levy, R. Nicholls, M.L. Parry, and S.R. Gaffin, 'Climate and Socio-Economic Scenarios for Global-Scale Climate Change Impacts 
Assessments: Characterising the SRES Storylines,' Global Environmental Change 20 (2010):577-85.

Bangladesh Bureau of Statistics (BBS),Agriculture Sample Survey 2005. Dhaka, Bangladesh: BBS, People’s Republic of Bangladesh, 2005a.

BBS, Household Income and Expenditure Survey 2004, Dhaka, Bangladesh: BBS, People's Republic of Bangladesh, 2005b.

Block, P., K. Strzepek, M. Rosegrant and X. Diao, 'Impacts of Considering Climate Variability on Investment Decisions in Ethiopia,'Agricultural Economics 39 (2008):171-81.

Calzadilla, A.,T. Zhu, K. Rehdanz, R.S.J.Tol,andC. Ringler,'Economywide Impacts of Climate Change on Agriculture in Sub-Saharan Africa,'Discussion Paper 873, International Food Policy Research Institute, Washington, DC, 2009.

Cassman, K.G., P. Grassini, and J. vanWart, 'Crop Yield Potential, Yield Trends, and GlobalFood Security in a Changing Climate,' in D. Hillel and C. Rosenzweig, Handbook of Climate Change and Agroecosystems: Impacts, Adaptation, and Mitigation, London: Imperial College Press, 2011.

del Ninno, C., P.A. Dorosh, L.C. Smith, and D.K. Roy,The 1998 Floods in Bangladesh: Disaster Impacts, Household Coping Strategies, and Response, Research Report 122, International Food Policy Research Institute, Washington, DC, 2001.

Dervis, K., J. de Melo and S. Robinson,General Equilibrium Models for Development Policy, New York: Cambridge University Press, 1982.

Diao, X. and J. Thurlow, 'Chapter Two: A Recursive Dynamic Computable General Equilibrium Model,' in X. Diao, J. Thurlow, S. Benin, and S. Fan (eds.), Agricultural Strategies in Africa: Evidence from Economywide Simulation Models, International Food Policy Research Institute, Washington, DC, forthcoming.

Dimaranan, B. (ed.),Global Trade, Assistance and Production: The GTAP 6 Database, West Lafayette, IN: Purdue University,Center for Global Trade Analysis, 2006.

Dorosh, P. and J. Thurlow, 'A 2005 Social Accounting Matrix (SAM) for Bangladesh,' International Food Policy Research Institute, Washington, DC, 2008.

Füssel, H.-M. and R.J.T. Klein, 'Climate Change Vulnerability Assessments: An Evolution of Conceptual Thinking,’ Climatic Change (2006) 75:301-29.

Hassan, R., 'The Double Challenge of Adapting to Climate Change While Accelerating Development in Sub-Saharan Africa,' Environment and Development Economics 15 (2010):661-85.

Hertel, T.W., M.B. Burke, and D.B. Lobell, 'The Poverty Implications of Climate-Induced Crop Yield Changes by 2030,' Global Environmental Change20 (2010):577-85. 
IWM and CEGIS, Investigating the Impact of Relative Sea Level Rise on Coastal Communities and their Livelihoods in Bangladesh, Final report to the Government of Bangladesh, Dhaka, 2007.

Tol, R.S.J., 'The Economic Effects of Climate Change,' Journal of Economic Perspectives23 (2009):29-51.

Yu, W. M. Alam, A. Hassan, A.S. Khan, A. Ruane, C. Rosenzweig, D.C. Major, and J. Thurlow,Climate Change Risks and Food Security in Bangladesh. London: Earthscan, 2010.

World Bank, World Development Indicators Online. Washington, DC (accessed June 2011). 